\title{
Anthropological and Perceptual Predictors Affecting the Ranking in Arm Wrestling Competition
}

\author{
Predictores Antropológicos y Perceptuales que Afectan \\ la Clasificación en la Competencia de Fuerza
}

Selcuk Akpinar*; Raif Zileli**; Emre Senyüzlï*** \& Seydi A. Tunca***

AKPINAR, S.; ZILELI, R.; SENYÜZLÜ, E. \& TUNCA, S. A. Anthropological and perceptual predictors affecting the ranking in arm wrestling competition. Int. J. Morphol., 31(3):832-838, 2013.

SUMMARY: The purpose of this study was to investigate the predictors contributing to be in the first three places with right and left arm in armwrestling. Seventy-three male senior armwrestlers competed in Turkish National Championship voluntarily participated in this study. Some participants competed with both arms. Two samples were composed of according to the participant competition category, for right (69 participants) and left arm (65 participants). The data were collected from eight different weight classes. Handgrip strength, auditory reaction time, forearm length, and forearm circumference were determined as the predictors. All the measurements were taken after weigh-ins had been done and before the first day of national championship competition. Logistic regression analysis was conducted to predict whether a competitor in armwrestling would be in the first three places either with right or left arm, to be a winner or non-winner. Relative handgrip strength was found a significant predictor for both right and left arm ranking ( $\mathrm{p}<0.05$ ). Auditory reaction time was found a significant predictor only for right arm ranking $(\mathrm{p}<0.05)$ and forearm circumference was found a significant predictor only for left arm ranking $(\mathrm{p}<0.05)$. These results suggest that strength can be viewed as the main predictor in left arm ranking; however, auditory reaction time is also an important factor to be in the first three places in right arm ranking. Thus, competitors should also focus to improve this perceptual skill.

KEY WORDS: Handgrip strength; Auditory Reaction Time; Forearm length; Forearm Circumference; Armwrestling.

\section{INTRODUCTION}

Armwrestling is accepted to be one of the oldest sports. Researchers stated that armwrestling could be traced all the way back to ancient Egypt. This is based on a painting depicting a type of arm wrestling found in an Egyptian tomb dating to about 2000 B.C. It has started to be very popular in the last century because it does not require many types of equipment and does not have many rules. The first rules for armwrestling was set up and the first organized competition carried out almost 60 years ago in California, USA (Usanov \& Gugina, 2012). Nowadays, it is a genuinely international sport and spread out all over the world.

In armwrestling, the competitors are facing one another. They lock their hands with their elbows firmly planted on the flat surface, and each attempts to force the others arm down to the table. Armwrestling involves primary (medial rotation of the upper arm, pronation of the forearm and hand, flexion of the wrist) and secondary (flexion of the arm and forearm) movements, which recruit the participation of some muscles, such as Pectoralis Major (PM), Biceps Brachii (BB), Pronator Teres (PT) and Flexor Carpi Ulnaris (FCU) muscles. In fact, the PM and FCU muscles participate as agonists in the simulated armwrestling whereas the $\mathrm{BB}$ and PT muscles seem to perform secondary functions (Silva et al., 2009). Besides the muscle strength, arm wrestlers also use different techniques like top-roll and hook. In toprolling, competitor tries to put his or her hand up opponent's palm. The main aim of the hook technique is to force the opponent's hand back and expose his or her wrist by twisting your wrist towards you (McKay \& McKay, 2009).

In armwrestling competition, the referee starting the match will be deemed head referee of that particular match. Assistant referee will watch for elbow fouls at start of mat-

\footnotetext{
"Physical Education and Sport Department, Faculty of Education, Nevsehir University, Nevsehir, Turkey.

** Physical Education and Sport Department, Bilecik Seyh Edabali University, Bilecik, Turkey.

*** School of Physical Education and Sport, Gazi University, Ankara, Turkey.
} 
ch and assist in assuring a fair start. In a regular match, assistant referee properly aligns the competitors' hands. Then, head referee starts the match with a "Ready...Go!" signal in an unspecified cadence (World Armwrestling Federation, 2009).

One may think that arm strength is the main contributing factor to winning an armwrestling match. However, armwrestling is not only a "strength" sport, but also a sport with technique and speed (Song et al., 2007). In fact, studies with armwrestling are very limited in the literature. This draws our attention to search for parameters contributing to winning in armwrestling. Therefore, the purpose of this study was to investigate the factors contributing to be in the first three places with right and left arm in armwrestling. For this purpose, we have determined some anthropological and perceptual predictors that can be thought as factors affecting to be a winner or non-winner. Handgrip strength, forearm circumference, and forearm length were determined as anthropological predictors whereas auditory reaction time was determined as a perceptual predictor. Handgrip strength was taken as the first predictor to win the match. Handgrip strength is often used in many sports, since hand dynamometry is simple, not expensive, and a well-established method for assessing the strength of wrist and digits flexor muscles. Some researchers reported high test-retest reliability of handgrip strength in children and adolescent males (Clerke et al., 2005; Gerodimos, 2012). As the head referee starts the match with a "Go" signal, it is important for a competitor to react very fast (Song et al.) to this stimulus to force the others arm down to the table. Thus, we took auditory reaction time as the second predictor. Some limb measurements, e.g. forearm length, and forearm circumference, are also used for the talent identification (Usanov \& Gugina), thus, we took these two parameters as the third and fourth predictors.

\section{MATERIAL AND METHOD}

The total number of 73 male senior armwrestlers voluntarily participated in this study. All armwrestlers participated in this study competed in Turkish National Championship. However, we could not reach all participants in the championship. Please note that we have searched the possible predictors for being a winner or non-winner in armwrestling competition for both right and left ranking. Most of the participants competed with both arms. Sixtyone participants (right-handed $=30$, ambidextrous $=15$, and left-handed=16) competed with both arms, 8 of them (righthanded $=8$ ) competed with their right arms only, and 4 of them (left-handed=4) competed with their left arms only.
Handedness was determined using a modified version of the Edinburgh Handedness Inventory (Oldfield, 1971). As we had both right and left ranking, two samples were composed of according to the participant competition category, for right and left arm. However, all the data collection procedures, equipments and applied statistical analyses were the same for both sample groups. The sample group for right ranking consisted of 69 male participants $(\mathrm{M}($ age $)=28.46 \pm 6.6$; right-handed $=38$, ambidextrous $=15$, and left-handed $=16$ ) . The sample group for left ranking consisted of 65 male participants $(\mathrm{M}($ age $)=28.18 \pm 6.52$; right-handed $=30$, ambidextrous $=15$, and left-handed $=20$ ). The participants from both right and left ranking group computed in the 8 different weight classes $(0-60 \mathrm{~kg}, 65 \mathrm{~kg}, 70 \mathrm{~kg}, 75 \mathrm{~kg}, 80$ $\mathrm{kg}, 85 \mathrm{~kg}, 90 \mathrm{~kg}$, and $100 \mathrm{~kg}$ ). The Ethics Committee of $\mathrm{Nevs}_{s}$ ehir University, Turkey approved this study.

The aim of this study was to investigate the factors contributing to be in the first three places with right and left arm in armwrestling. For this purpose, we have determined four predictors; handgrip strength, auditory reaction time, forearm length, and forearm circumference. All the measurements were taken after weigh-ins had been done and before the first day of competition start time. The measurements were taken by two researchers and done in a silent and fresh room so that each participant felt very comfortable. All the measurements for one arm took approximately $5 \mathrm{~min}$. As there were sixty-one participants computed with both arms, 10 min break was provided between arm measurements. The measurements were started with forearm length and forearm circumference and then continued with auditory reaction time. Finally, the measurement of handgrip strength was applied to the participants.

Forearm length measurement was taken as length of radius, from radiale (proximal point on the lateral side of the head of the radius) to stylion (most distal point on the styloid process of the radius).

Forearm circumference was measured in supination at a point $12 \mathrm{~cm}$ distal to the tip of the olecranon in a flexed elbow at $90^{\circ}$ and using a flexible tape measure. This was applied closely to the skin, but without causing compression (Anakwe et al., 2007).

Simple auditory reaction time was obtained using a multi-choice reaction timer (Lafayette Instruments Company). Participants put their index finger on the key and were instructed to press the key as rapidly as possible when they heard the auditory stimulus.

Handgrip strength measurements were taken with a 
portable digital hand dynamometer (Jamar, EN-120604). Each participant performed a standardized warm-up that included one or two preliminary trials for familiarization with the recording procedure and instrumentation. The participants were seated on a chair with the shoulder adducted and neutrally rotated. Whereas the forearm and wrist were set in neutral position, the elbow was flexed at $90^{\circ}$ (Gerodimos; Holm et al., 2008). The testing protocol consisted of three maximal isometric contractions for 3 - 5 $\mathrm{s}$, on competed hand. In order to avoid from the effect of fatigue, a rest period of at least $60 \mathrm{~s}$ was provided to the participants between trials. The participants were told to put maximal force on the dynamometer. The result of handgrip strength was provided to the participants after each trial. The maximal strength value $(\mathrm{kg})$ of three trials was used for the analysis. As the participants were from 8 different weight classes, relative handgrip strength (handgrip strength / kg of body mass) value was used for the statistical analysis.

Data were analyzed using SPSS 18 statistical software. Logistic regression analysis was performed to predict whether a competitor in armwrestling would be in the first three places either with right or left arm, to be a winner or non-winner. We defined the winners as the competitors who were in the first three places in the armwrestling competition and non-winners as the competitors who were in the fourth or upper places in the armwrestling competition. We also tested collinearity following logistic regression analysis. As SPSS does not have an option for producing collinearity diagnostics in logistic regression, we obtained statistics such as the tolerance and VIF by simply running a linear regression analysis using the same outcome and predictors. As we tested predictors to be a winner or non-winner for right and left arm, we conducted two separate logistic analyses. The level of significance was set to $\mathrm{p}<0.05$.

\section{RESULTS}

Right Arm Ranking. The average and standard deviation of the predictors in right arm ranking were provided in Table I. A logistic regression analysis was conducted for the statistical analysis with relative handgrip strength, auditory reaction time, forearm circumference, and forearm length being as predictors for the analysis.

A test of the full model against a constant only model was statistically significant, indicating that the predictors as a set reliably distinguished between winners and non-winners (chi square $=31.18, \mathrm{p}<.000$ with $\mathrm{df}=4$ ). Nagelkerke's R2 is the most-reported of the R-squared estimates. In our case, it was 0.533 , indicating a moderate relationship of $53.3 \%$ between the predictors and the prediction. Hosmer and Lemeshow goodness-of-fit statistic was greater than 0.05 ,

Table I. Participants’ Average Auditory Reaction Time, Relative Handgrip Strength, Forearm Circumference, and Forearm Length in Right Arm Ranking.

\begin{tabular}{lcc}
\hline & Winner $(\mathrm{n}=18)$ & Non-winner $(\mathrm{n}=51)$ \\
& $\mathrm{M} \pm \mathrm{SD}$ & $\mathrm{M} \pm \mathrm{SD}$ \\
\hline Auditory Reaction Time $(\mathrm{ms})$ & $123 \pm 16.8$ & $146.67 \pm 15.8$ \\
Relative Handgrip Strength & $0.92 \pm 0.17$ & $0.82 \pm 0.13$ \\
For earm Circumference $(\mathrm{cm})$ & $33.39 \pm 3.37$ & $32.5 \pm 2.91$ \\
For earm Length $(\mathrm{cm})$ & $27.44 \pm 1.61$ & $26.97 \pm 1.15$ \\
\hline
\end{tabular}

Table II. Classification Tables For Right Arm Ranking; Step 0: Before The Analysis, Step 1: After The Analysis.

\begin{tabular}{|c|c|c|c|c|c|}
\hline & \multirow{2}{*}{\multicolumn{2}{|c|}{ Observed }} & \multicolumn{3}{|c|}{$\begin{array}{l}\text { Predicted } \\
\text { Right Ranking }\end{array}$} \\
\hline & & & Winner & Non-winner & Percentage Correct \\
\hline \multirow[t]{3}{*}{ Step 0} & \multirow{2}{*}{ Right Ranking } & Winner & 0 & 18 & 0 \\
\hline & & Non-winner & 0 & 51 & 100.0 \\
\hline & \multicolumn{4}{|c|}{ Overall Percentage } & 74.0 \\
\hline \multirow[t]{3}{*}{ Step 1} & Right & Winner & 13 & 5 & 72.2 \\
\hline & Ranking & Non-winner & 3 & 48 & 94.1 \\
\hline & \multicolumn{4}{|c|}{ Overall Percentage } & 88.4 \\
\hline
\end{tabular}


implying that the model's estimates fit the data at an acceptable level (Field, 2009).

In the Classification table, the columns are the two predicted values of the dependent, while the rows are the two observed (actual) values of the dependent. In a perfect model, all cases will be on the diagonal and the overall percent correct will be $100 \%$. In this study, $72.2 \%$ were correctly classified for the winner group and $94.1 \%$ for non-winner group (Table II). Overall $88.4 \%$ (step 1 in Table II) were correctly predicted. This is a considerable improvement on the $74 \%$ (step 0 in Table II) correct classification with the constant model so we know that the model with predictors is a significantly better mode.

The Wald statistic and associated probabilities provide an index of the significance of each predictor in the equation. The Wald statistic has a chi-square distribution. The simplest way to assess Wald is to take the significance values and if less than .05 reject the null hypothesis as the variable does make a significant contribution. In our case, we note that auditory reaction time and relative handgrip strength contributed significantly to the prediction $(\mathrm{p}=0.002$ and $\mathrm{p}=$ 0.023 , respectively) but forearm length and forearm circumference did not $(\mathrm{p}=0.44$ and $\mathrm{p}=0.10$, respectively) (Table III).

For the assumption of logistic regression, collinearity statistics was also checked with linear regression analysis (Field). The result of the linear regression analysis showed tolerance and VIF values as 0.86 and 1.16 for auditory reaction time, 0.83 and 1.20 for relative handgrip strength and forearm circumference, and 0.91 and 1.10 for forearm length, respectively. For the collinearity statistics, a tolerance values less than 0.1 (Menard, 1995) and a VIF value greater than 10 (Myers, 1990) are cause for concern for the parameters of a regression model. In our case, therefore, it is safe to indicate that our logistic regression model is reliable to predict winner or non-winner in an armwrestling competition.

Table III. The Result of Wald Statistics in Logistic Regression Analysis For Right Arm Ranking.

\begin{tabular}{lcccccr}
\hline & $B$ & S.E. & Wald & $d f$ & Sig. & $\operatorname{Exp}(B)$ \\
\hline Auditory Reaction Time & .99 & .32 & 9.46 & 1 & .002 & 2.71 \\
Relative Handgrip Strength & -6.34 & 2.79 & 5.15 & 1 & .023 & .002 \\
Forearm Circumference & -.24 & .15 & 2.69 & 1 & .101 & .78 \\
Forearm Length & -.24 & .318 & .58 & 1 & .447 & .79 \\
Constant & 7.67 & 12.07 & .40 & 1 & .525 & 2146.38 \\
\hline
\end{tabular}

Table IV. Participants' Average Auditory Reaction Time, Relative Handgrip Strength, Forearm Circumference, and Forearm Length In Left Arm Ranking.

\begin{tabular}{lcc}
\hline & Winner $(\mathrm{n}=18)$ & Non-winner $(\mathrm{n}=51)$ \\
& $M \pm S D$ & $M \pm S D$ \\
\hline Auditory Reaction Time $(\mathrm{ms})$ & $133 \pm 15.1$ & $146.52 \pm 24.5$ \\
Relative Handgrip Strength & $0.92 \pm 0.17$ & $0.80 \pm 0.13$ \\
For earm Circumference $(\mathrm{cm})$ & $32.4 \pm 2.85$ & $31.1 \pm 2.9$ \\
For earm Length $(\mathrm{cm})$ & $27.31 \pm 1.14$ & $26.85 \pm 1.36$ \\
\hline
\end{tabular}

Table V. Classification Tables for Left Arm Ranking; Step 0: Before The Analysis, Step 1: After The Analysis.

\begin{tabular}{lllccc}
\hline & \multicolumn{2}{c}{ Observed } & \multicolumn{3}{c}{ Predicted } \\
& & Right Ranking & \\
& & Winner & Non-winner & Percentage Correct \\
\hline Step 0 & Right Ranking & Winner & 0 & 19 & .0 \\
& & Non-winner & 0 & 46 & 100.0 \\
& Overall Percentage & & & 70.8 \\
Step 1 & Right & Winner & 11 & 8 & 57.9 \\
& ranking & Non-winner & 3 & 43 & 93.5 \\
& Overall Percentage & & & 83.1 \\
\hline
\end{tabular}


Left Arm Ranking. The average and standard deviation of the predictors in left arm ranking were provided in Table IV. Similar to right arm ranking, a logistic regression analysis was conducted for the statistical analysis with the same predictors for the analysis.

A test of the full model against a constant only model was statistically significant, indicating that the predictors as a set reliably distinguished between winners and non-winners (chi square $=21.23, \mathrm{p}<0.000$ with $\mathrm{df}=4$ ). Nagelkerke's R2 is the most-reported of the R-squared estimates. In our case, it was 0.40 , indicating a moderate relationship of $40 \%$ between the predictors and the prediction.

Hosmer and Lemeshow goodness-of-fit statistic was greater than .05 , implying that the model's estimates fit the data at an acceptable level.

In the Classification table, the columns are the two predicted values of the dependent, while the rows are the two observed (actual) values of the dependent. For the left ranking, 58\% were correctly classified for the winner group and $93.5 \%$ for non-winner group (Table V). Overall $83.1 \%$ (step 1 in Table V) were correctly classified. This is a considerable improvement on the $70.8 \%$ (step 0 in Table V) correct classification with the constant model so we know that the model with predictors is a significantly better mode.

The Wald statistic showed that relative handgrip strength and forearm circumference contributed significantly to the prediction ( $\mathrm{p}=0.005$ and $\mathrm{p}=0.04$, respectively) but auditory reaction time and forearm length did not $(\mathrm{p}=0.24$ and $\mathrm{p}=0.15$, respectively) (Table VI).

We also tested collinearity following our logistic regression analysis. The result of the linear regression analysis showed tolerance and VIF values as 0.76 and 1.09 for auditory reaction time, 0.7 and 1.42 for relative handgrip strength, 0.69 and 1.44 for forearm circumference, and 0.92 and 1.09 for forearm length, respectively. Therefore, it is safe to indicate that our logistic regression model is reliable to predict winner or non-winner in an armwrestling competition.

Table VI. The Result of Wald Statistics In Logistic Regression Analysis For Left Arm Ranking.

\begin{tabular}{lcccccc}
\hline & B & S.E. & Wald & df & Sig. & $\operatorname{Exp}(\mathrm{B})$ \\
\hline Auditory Reaction Time & .02 & .02 & 1.39 & 1 & .238 & 1.02 \\
Relative Handgrip Strength & -8.80 & 3.11 & 8.03 & 1 & .005 & .000 \\
Forearm Circumference & -.28 & .14 & 3.68 & 1 & .041 & .76 \\
Forearm Length & -.43 & .30 & 2.1 & 1 & .147 & .65 \\
Constant & 25.8 & 11.46 & 5.06 & 1 & .024 & 1.60 \\
\hline
\end{tabular}

\section{DISCUSSION}

Armwrestling has become a popular sport in all over the world. Even though one may consider arm strength as the main contributing factor for winning, strength is not seen the only factor for winning (Song et al.). Speed and technique are also thought to be effective in this sport. In this study, we tried to find the possible predictors for winning a match in armwrestling competition. For this purpose, we determined three anthropological and one perceptual predictor; relative handgrip strength, forearm circumference, forearm length, and auditory reaction time. Logistic regression analysis displayed different results for right arm and left arm ranking. Whereas auditory reaction time and relative handgrip strength were found to be significant predictors in right arm ranking for being a winner or non-winner, relative handgrip strength and forearm circumference were found to be significant predictors in left arm ranking.
In armwrestling, it is very crucial to react fast to the head referee "go" signal to start the match in order to force the others arm down to the table before the opponent attempt. Thus, auditory reaction time plays one of the major roles to win the match and this was supported with the result in right arm ranking. Interestingly, auditory reaction time was not found a significant predictor in left arm ranking although competitors in winner group had faster auditory reaction time $(\mathrm{M}=133 \pm$ $15.1 \mathrm{~ms})$ than that of non-winner group $(\mathrm{M}=146 \pm 24.5 \mathrm{~ms})$. This perceptual skill is widely used to evaluate neuromuscularphysiological responses in many sports and one of the main factors for successful performance (Guissard \& Duchateau, 1990; Landers \& Boutcher, 1986). Ertan et al. (2005) stated that successful performance of an archer is related to having a quick reaction to the clicker's fall (sound) of the bow in archery. Similar to the archery, in the sprint start, auditory reaction time 
has also an effect on the sprint performance (Pilianidis et al., 2012; Pain \& Hibbs, 2007). The obtained result especially in right arm ranking is consistent with the positive effect of auditory reaction time on the overall performance.

Handgrip strength is generally used to measure the maximum isometric strength of the hand and forearm muscles. It is important for any sport in which the hands are used. Strength is also thought to be one of the important factors to win a match in armwrestling (Mazurenko, 2012). In fact, relative handgrip strength was found to be a significant predictor for being a winner or non-winner in armwrestling competition for both right and left arm ranking in this study. This is not a surprising result as the competitors aims are to force the others arm down to the table. Thus, being stronger than the opponent can give an advantage to win the match if both competitors have the same auditory reaction time and techniques.

The other dependent variable used in this study predicting to be a winner or non-winner in armwrestling was forearm circumference. Forearm circumference was found to be a predictor of maximum handgrip strength in many studies (Anakwe et al.; Fraser et al., 1999; Nicolay \& Walker, 2005). In this study, forearm circumference together with relative handgrip strength was found a significant predictor in left arm ranking. Although forearm circumference value in winner group $(\mathrm{M}=33.39 \pm 3.37 \mathrm{~cm})$ in right arm ranking was more than non-winner group $(\mathrm{M}=32.5 \pm 2.91 \mathrm{~cm})$, it did not reach the significant level for being a predictor. It is still noteworthy to consider forearm circumference as a factor to be a winner in armwrestling.

Anthropometric measurements have been using for talent identification for many sports (Alacid et al., 2011; Almagia et al., 2008; 2009; Fonseca et al., 2010). Specifically, in some countries, forearm length is used as a criterion to select talented armwrestlers (Usanov \& Gugina). It was previously stated that forearm length had a positive correlation with the maximum handgrip strength (Nicolay \& Walker). Forearm length values were found very similar for winners and nonwinners in this study although these two groups had different relative handgrip strength values. Forearm length may be effective to apply different techniques (the top-roll or the hook) during the match as it may give an advantage to put hand over the opponent's palm. However, we did not aim to search the effect of forearm length on applying techniques. The result mainly showed that forearm length was not a predictor for being a winner or non-winner for both right and left arm ranking in armwrestling. In fact, previous study with woman armwrestlers displayed a significant effect of forearm length in right arm ranking (Akpinar et al., 2012). Thus, requirements to be successful in armwrestling are different between man and woman armwrestlers.
Armwrestling has been increasing its popularity for the last two decades. However, scientific studies about armwrestling are very limited in the literature. This study aimed to investigate possible predictors to be a winner or non-winner in armwrestling competition. Overall, relative handgrip strength was found to be a significant predictor for both right and left arm ranking. Competitors in this sport mostly perform strength training in their practice regime (Mazurenko). However, Strength itself cannot be the main factor to win a match in armwrestling. Competitor should also improve their auditory reaction time, which was found a significant predictor in right arm ranking. Speedy response in order to set muscles into motion will definitely give an advantage to apply appropriate technique and win the match. Thus, athletes in this sport should allocate some time in their practice to enhance this vital sporting requirement. Forearm circumference also found a significant predictor especially for left arm ranking. For this reason, strength training for these athletes should also focus on forearm muscles, which can also improve handgrip strength. Forearm length was not found a significant predictor in this study. Therefore, this anthropometric measurement does not need to be used for the talent identification in armwrestling. It can be concluded that the predictors to be a winner or non-winner in armwrestling are not exactly the same for right and left arm ranking. Whereas competitors in right arm ranking should focus to improve their auditory reaction time and handgrip strength, competitors in left arm ranking should focus to improve their handgrip strength and forearm circumference.

AKPINAR, S.; ZILELI, R.; SENYÜZLÜ, E. \& TUNCA, S. A. Predictores antropológicos y perceptuales que afectan la clasificación en la competencia de fuerza. Int. J. Morphol., 31(3):832-838, 2013.

RESUMEN: El objetivo de este estudio fue investigar los predictores que contribuyen a clasificar en los tres primeros lugares en la lucha de fuerza de brazos (vencidas o pulsadas) con el brazo derecho e izquierdo. Setenta y tres hombres luchadores senior compitieron en el Campeonato Nacional de Turquía y participaron voluntariamente en este estudio. Algunos participantes compitieron con ambos brazos. Dos muestras fueron conformadas de acuerdo con la categoría de competencia del participante, para el brazo derecho (69 participantes) y el brazo izquierdo (65 participantes). Los datos se obtuvieron para 8 categorías de peso. La fuerza de prensión, tiempo de reacción auditiva, largo del brazo y circunferencia del antebrazo se determinaron como predictores. Todas las medidas fueron tomadas después de pesaje clasificatorio y antes del primer día de competición. Un análisis de regresión logística se realizó para predecir si un competidor en lucha de fuerza estaría en los tres primeros lugares ya sea con el brazo derecho o izquierdo, para ser un ganador o no ganador. La fuerza de prensión relativa resultó un predictor significativo para la clasificación tanto en el brazo derecho e izquierdo ( $\mathrm{p}<0,05)$. El tiempo de reacción auditiva se encontró un predictor significativo sólo para la clasificación del brazo derecho $(\mathrm{p}<0,05)$ y la circunferencia del antebrazo un predictor significativo sólo para el brazo izquierdo $(\mathrm{p}<0,05)$. Estos resultados sugieren que la fuerza puede ser vista como el principal predictor en la clasificación para el brazo izquierdo, sin embargo, el tiempo de reac- 
ción auditiva es también un factor importante para estar en los tres primeros lugares de la clasificación para el brazo derecho. Por lo tanto, los competidores también deben centrarse en mejorar esta habilidad perceptual.

PALABRAS CLAVE: Fuerza de prensión; Tiempo de reacción auditiva; Longitud del antebrazo; Circunferencia del antebrazo; Lucha de Brazos.

\section{REFERENCES}

Akpinar, S.; Zileli, R.; Senyüzlü, E. \& Tunca, S.A. Predictors affecting the ranking in women armwrestling competition. Monten. J. Sports Sci. Med., 1:15-20, 2012.

Alacid, F.; Muyor, J. M. \& Lopez-Minarro, P.A. Anthropometric profile of young male sprint canoeist. Int. J. Morphol., 29(3):835-40, 2011.

Almagia, A. F.; Rodrigez, R. F. J.; Barraza, G. F. O.; Lizana, P. J. \& Jorquera, A. C. A. Anthropometric profile of female football-soccer Chilean players. Int. J. Morphol., 26(4):817-21, 2008.

Almagià, A. F.; Rodrigez, R. F. J.; Barraza, G. F. O.; Lizana, P. J.; Ivanovic, D. \& Binvignat, G. O. Anthropometric profile of professional volleyball Southamerican players. Int. J. Morphol., 27(1):53-7, 2009.

Anakwe, R. E.; Huntley, J. S. \& McEachan, J. E. Grip strength and forearm circumference in a healthy population. J. Hand Surg. Eur. Vol., 32(2):203-9, 2007.

Clerke, A. M.; Clerke, J. P. \& Adams, R. D. Effects of hand shape on maximal isometric grip strength and its reliability in teenagers. $J$. Hand Ther., 18(1):19-29, 2005.

Ertan, H.; Kentel, B. B.; Tümer, S. T. \& Korkusuz, F. Reliability and validity testing of an archery chronometer. J. Sports Sci. Med., 4:95104, 2005.

Field, A. Discovering statistics using SPSS. $3^{\text {rd }}$ ed. London, Sage, 2009. pp.185-200.

Fonseca, C. L. T.; Fernandes, P. R. \& Fernandes, J. Analysis of Anthropometrical Profile of Brazilian Junior Volleyball Team. Int. J. Morphol., 28(4):1035-41, 2010.

Fraser, A.; Vallow, J.; Preston, A. \& Cooper, R. G. Predicting 'normal' grip strength for rheumatoid arthritis patients. Rheumatology (Oxford), 38(6):521-8, 1999.

Gerodimos, V. Reliability of handgrip strength test in basketball players. J. Hum. Kinet., 31:25-36, 2012.

Guissard, N. \& Duchateau, J. Electromyography of the sprint start. J. Hum. Movement Studies, 18:97-106, 1990.

Holm, I.; Fredriksen, P.; Fosdahl, M. \& Vøllestad, N. A normative sample of isotonic and isokinetic muscle strength measurements in children 7 to 12 years of age. Acta Paediatr., 97(5):602-7, 2008.
Landers, D. M.; Boutcher, S. H. \& Wang, M. Q. A psychobiological study of archery performance. Res. Q. Exerc. Sport, 57(3):236-44, 1986.

Mazurenko, I. Training diary for armwrestling. Gdynia, Mazurenko Armwrestling Promotion Sp. z o.o., 2012. pp.5-15.

McKay, B. \& McKay, K. Going over the top: How to dominate in arm wrestling, 2009. Available in: http://artofmanliness.com/2009/03/20/ the-art-of-manliness-guide-to-arm-wrestling/

Menard, S. Applied logistic regression analysis. Sage university paper series on quantitative applications in the social sciences. Thousand Oaks, Sage, 1995. pp.120-45.

Myers, R. Classical and modern regression with applications. $2^{\text {nd }}$ ed. Boston, Duxbury, 1990. pp.85-127.

Nicolay, C. W. \& Walker, A. L. Grip strength and endurance: Influences of anthropometric variation, hand dominance, and gender. Int. J. Ind. Ergon., 35(7):605-18, 2005.

Oldfield, R. C. The assessment and analysis of handedness: the Edinburgh inventory. Neuropsychologia, 9(1):97-113, 1971.

Pain, M. T. \& Hibbs, A. Sprint starts and the minimum auditory reaction time. J. Sports Sci., 25(1):79-86, 2007.

Pilianidis, T.; Kasabalis, A.; Mantzouranis, N. \& Mavvidis, A. Start reaction time and performance at the sprint events in the Olympic Games. Kinesiology, 44(1):67-72, 2012.

Silva, D. C.; Silva, Z.; Sousa, Gda C.; Silva, L. F.; Marques Kdo V.; Soares, A. B.; et al. Electromyographic evaluation of upper limb muscles involved in armwrestling sport simulation during dynamic and static conditions. J. Electromyogr. Kinesiol., 19(6):e448-57, 2009.

Song, Q.; Yu, Y.; Ge, Y.; Gao, Z.; Shen, H. \& Deng, X. A real-time EMGdriven arm wrestling robot considering motion characteristics of human upper limbs. Int. J. Human Robot., 4(4):645-70, 2007.

Usanov, E. I. \& Gugina, L. V. Armwrestling. $2^{\text {nd }}$ ed. Moscow, Yceb Nosobie, RVDN, 2012. pp.15-42.

World Armwrestling Federation. Rules of Armwrestling, 2009. Available in: http://www.worldarmwrestlingfederation.com/docpol.htm

Correspondence to:

Selçuk Akpınar, PhD

Nevs, ehir University, Faculty of Education

Physical Education and Sport Department

2000 Evler Mah. Zübeyda Hanım Cad. 50300 Nevs, ehir TURKEY

Email: sakpinar@nevsehir.edu.tr 